\title{
Production of $\mathrm{Mo}^{+}$Beams Using an Arc Discharge Ion Source
}

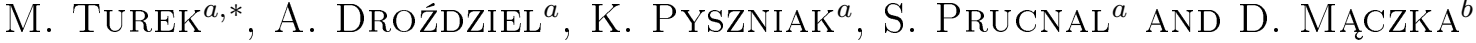 \\ ${ }^{a}$ Institute of Physics, Maria Curie-Skłodowska University in Lublin \\ pl. M. Curie-Skłodowskiej 1, 20-031 Lublin, Poland \\ ${ }^{b}$ National Center for Nuclear Studies, Świerk-Otwock, Poland
}

\begin{abstract}
A new method of $\mathrm{Mo}^{+}$ion beam production is presented in the paper. The method bases on the chemical sputtering/etching of the molybdenum parts (e.g. anode) of the arc discharge ion source by the chloride containing plasma. A mixture of $\mathrm{CCl}_{4}$ (or $\mathrm{CHCl}_{3}$ ) vapor and air was used as the feeding substance. The separated $\mathrm{Mo}^{+}$ beam current of approximately $18 \mu \mathrm{A}$ was achieved. The measurements of the ion current dependences on the discharge and filament currents as well as on the magnetic field flux density from the electromagnet surrounding the discharge chamber were performed in order to find the optimal working parameters of the ion source.
\end{abstract}

DOI: $10.12693 /$ APhysPolA.125.1388

PACS: 07.77.Ka, 34.80.Dp, 61.72.uj

\section{Introduction}

Ion implantation is one of the most popular and reliable methods of modification of physical properties of semiconductors, metals, polymers etc. A variety of ion sources were designed and tested in order to cope with the demands of producing stable and intense beams necessary e.g. for high-dose irradiations $[1,2]$.

In the case of refractory metals (including rare earths, which are important dopants in optoelectronics [3, 4] and spintronics [5]) several attempts was applied. Alloys characterized by the melting point lower than their components may be used as feeding substances for liquid metal ion sources [6]. Plasma sputtering [7] or laser ablation combined with electron cyclotron resonance [8] could also be successfully applied. Electron beam ion sources [9] especially with the high power evaporator/target heating systems seem also suitable for production of ions of non-volatile elements [10]. Very popular tools are different versions of high power MEVVA-type arc discharge ion source [11]. Recently, compact arc discharge ion sources equipped with an internal evaporator have been proposed [12-15]. Using chlorides (which usually have lower melting points than corresponding) appeared to be a successful strategy allowing production of e.g. $25 \mu \mathrm{A}$ of $\mathrm{Eu}^{+}$ using a ion source consuming power of $300 \mathrm{~W}$ [16].

Molybdenum implantations are often performed in order to improve corrosion resistance of metals and alloys like aluminum and steel $[17,18]$. Passive layers on the surface of stainless steel were also formed in order to improve its resistance to chemically aggressive environment [19]. The increase in hardness as well as elastic modulus of Mo implanted aluminum alloy was also observed [20]. High-fluence (up to $5 \times 10^{17} \mathrm{~cm}^{-2}$ ) implantations of zirconium and zircaloy- 4 were applied in order to study changes of aqueous corrosion resistance with the implantation fluence $[21,22]$. It should be noticed that

*corresponding author; e-mail: mturek@kft.umcs.lublin.pl
Mo and $\mathrm{S}$ co-implantations lead to the production of well-known solid lubricant $\mathrm{MoS}_{2}$ layers in $\mathrm{Al}_{2} \mathrm{O}_{3}, \mathrm{ZrO}_{2}$, and $\mathrm{SiO}_{2}$ layers [23].

In most of the cases $\mathrm{Mo}^{+}$beams were obtained using MEVVA sources. A very interesting method of Mo and other refractory metal ions based on their volatile compounds (e.g. carbonyls) and electron cyclotron resonance ion source [24].

In our paper we present the method of $\mathrm{Mo}^{+}$production that makes use of chemical sputtering of ion source parts (e.g. anode) made of molybdenum by chlorine contained in plasma inside the chamber of the arc discharge ion source [12]. The presence of $\mathrm{Mo}^{+}$ions in the extracted beam (treated as contaminants) were reported during the production of rare earths ions from their chlorides (e.g. $\mathrm{EuCl}_{3}$ ) [16]. We decided to use this effect to our advantage, using $\mathrm{CCl}_{4}$ and $\mathrm{CHCl}_{3}$ as feeding substances.

The paper contains brief description of the ion source and the experimental setup. The basic characteristic of the ion source, namely dependences of the ion current and discharge voltage on discharge and filament current are presented and discussed in order to determine optimal working parameters. The influence of the magnetic flux density from the external electromagnet coil the discharge chamber is placed in on the ion source performance is also under investigation.

\section{Experimental}

The ion source used for $\mathrm{Mo}^{+}$beam production was the cylindrical anode arc discharge model described in detail in [12-15]. Its schematic view is shown in Fig. 1. Both the anode and cathode filament mounts are made of molybdenum. For $\mathrm{Mo}^{+}$production purposes no internal evaporator was required, a short molybdenum gas feeding tube, connected with the long stainless steel capillary, was used instead. The discharge chamber, formed by anode and filament mounts separated by insulators made of boron nitride, has the internal diameter of $11 \mathrm{~mm}$ and the length of $\approx 20 \mathrm{~mm}$. A spiral filament made of tungsten wire is placed inside the chamber. It is the source of electrons that maintain the arc discharge burning in 
the region between the anode and the cathode. The filament (diameter of $0.75 \mathrm{~mm}$ ) is heated by the filament current $I_{\mathrm{c}}$ (up to $\approx 38 \mathrm{~A}$ ). The stabilized discharge current $I_{\mathrm{a}}$ may be set up to $4.5 \mathrm{~A}$. The discharge is initialized by setting the anode voltage $U_{\mathrm{a}}$ to approximately $100 \mathrm{~V}$ and increasing the $I_{\mathrm{c}}$. Soon after the ignition the discharge voltage stabilizes at lower values $(30-40 \mathrm{~V})$. The discharge chamber is surrounded by the electromagnet coil, whose aim is to compensate the magnetic field from the spiral cathode and to place the discharge region as close as possible to the extraction opening.

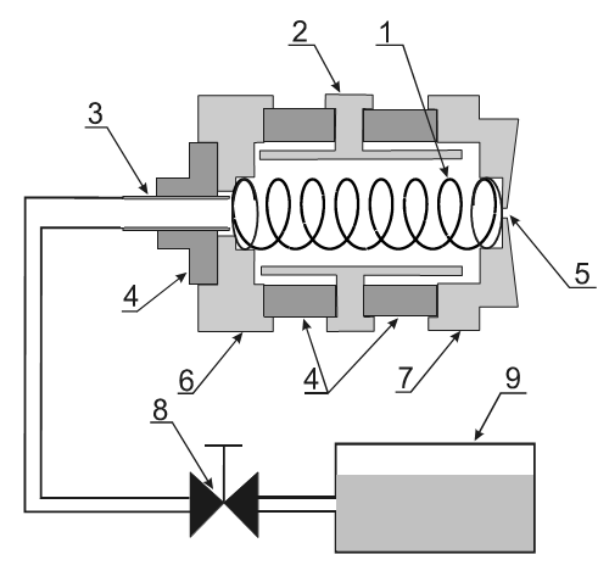

Fig. 1. Schematic drawing of the ion source: 1 - cathode filament, 2 - anode (Mo), 3 - gas inlet, 4 - insulators $(\mathrm{BN}), 5$ - extraction opening, 6, 7 - cathode filament mounts, 8 - dosing valve, 9 - container with the liquid $\mathrm{CCl}_{4} / \mathrm{CHCl}_{3}$ and air.

The mixture of $\mathrm{CCl}_{4}$ or $\mathrm{CHCl}_{3}$ vapors and air is transported via the dosing valve into the discharge chamber. The flow is approximately $10 \mathrm{mbar} \mathrm{cm}^{3} / \mathrm{s}$. It is known that plasma containing $\mathrm{Cl}_{2}$ and $\mathrm{Cl}$ etches metallic molybdenum fast $(\approx 20 \mathrm{~nm} / \mathrm{min})$, especially in elevated temperatures [25]. A small addition of oxygen (by using $\mathrm{CCl}_{4} / \mathrm{O}_{2}$ mixtures) makes this process several times faster [26]. $\mathrm{CCl}_{4}$ and $\mathrm{CHCl}_{3}$ were also chosen due to the fact that they are not as chemically aggressive to metal parts of the dosing valve as gaseous $\mathrm{Cl}_{2}$. Atoms of molybdenum in the discharge plasma are ionized by electron impact. Ions are extracted via the extraction hole (diameter of $0.8 \mathrm{~mm}$ ) using the voltage $V_{\text {ext }}=25 \mathrm{kV}$. The beam is formed using a standard triple lens system and then it passes a $90^{\circ}$ sector separating magnet. The separated beam is finally accelerated using $V_{\text {acc }}=75 \mathrm{keV}$. Finally, ion currents are measured using a Faraday cup placed behind the acceleration stage.

\section{Results}

Measurements were done approximately $30 \mathrm{~min}$ after the ignition, when the ion source worked stable. Figures $2 \mathrm{a}$ and $3 \mathrm{a}$ show the dependence of the separated $\mathrm{Mo}^{+}$current vs. the discharge current $I_{\mathrm{a}}$. The other working parameters (like filament current, magnetic field flux density, and the feeding gas flow) were kept constant.
One can observe increase of $I_{\text {ion }}$ with $I_{\text {a }}$ followed by the saturation of the $I_{\text {ion }}\left(I_{\mathrm{a}}\right)$ curve. This effect is better visible for $\mathrm{CHCl}_{3}$, one can even see a decrease of the ion current for larger $I_{\mathrm{a}}$. This could be due to several factors - one of them is increasing ion recombination probability, rising with the plasma density. Also the screening properties of plasma may degrade the efficiency of extraction. Let us note also that the discharge voltage rises with the $I_{\mathrm{a}}$, which was also observed for relatively volatile solids as Mn and In [12]. The discharge voltage in the range $40-50 \mathrm{~V}$ seems to be optimal for $\mathrm{Mo}^{+}$production. For both feeding substances the maximal $\mathrm{Mo}^{+}$ currents were $\approx 18 \mu \mathrm{A}$.
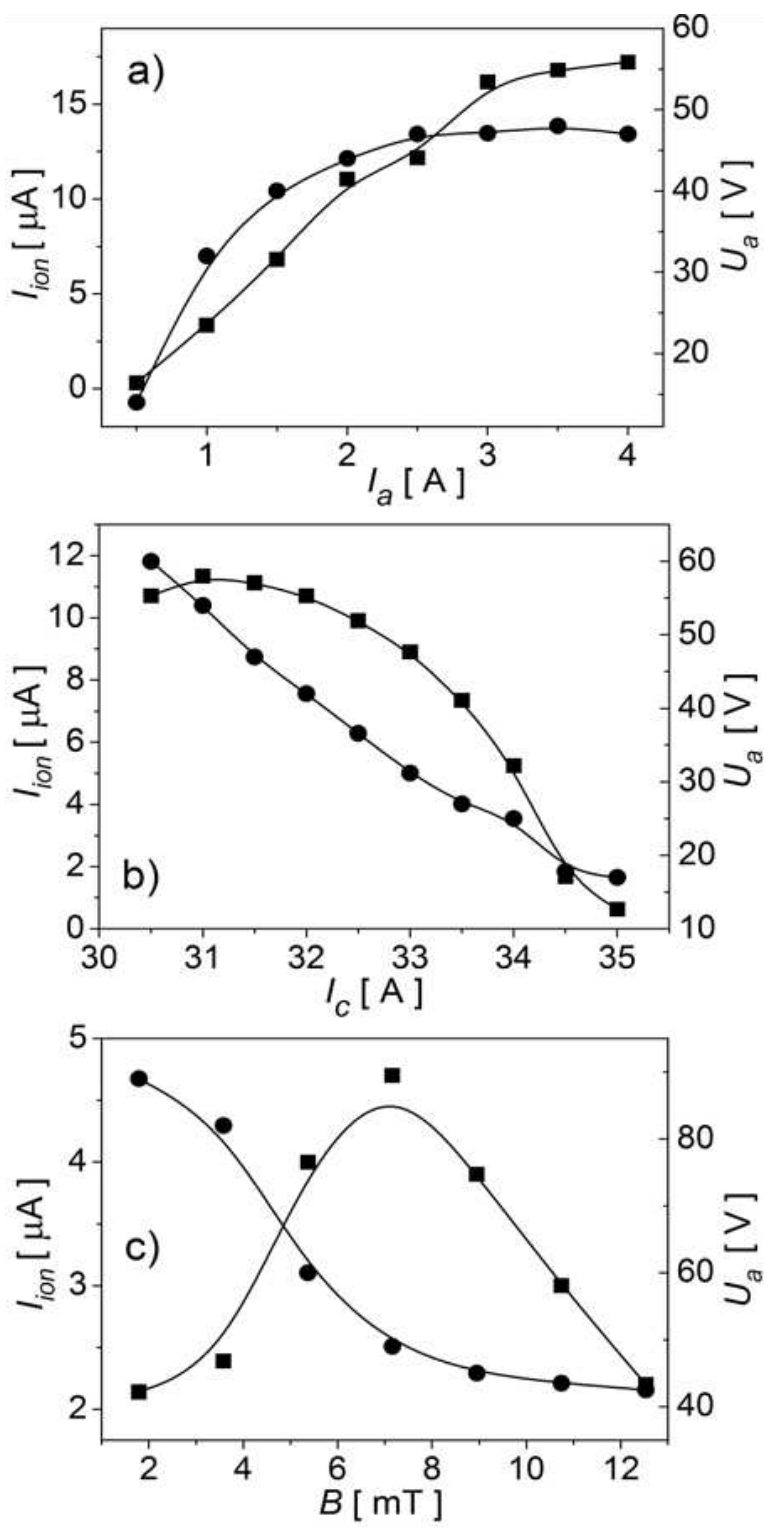

Fig. 2. Dependences of the ion current (squares) and the discharge voltage (full circles) on the discharge current (a), filament current (b), and magnetic flux density (c). The case of $\mathrm{CCl}_{4}$ as the feeding substance. 

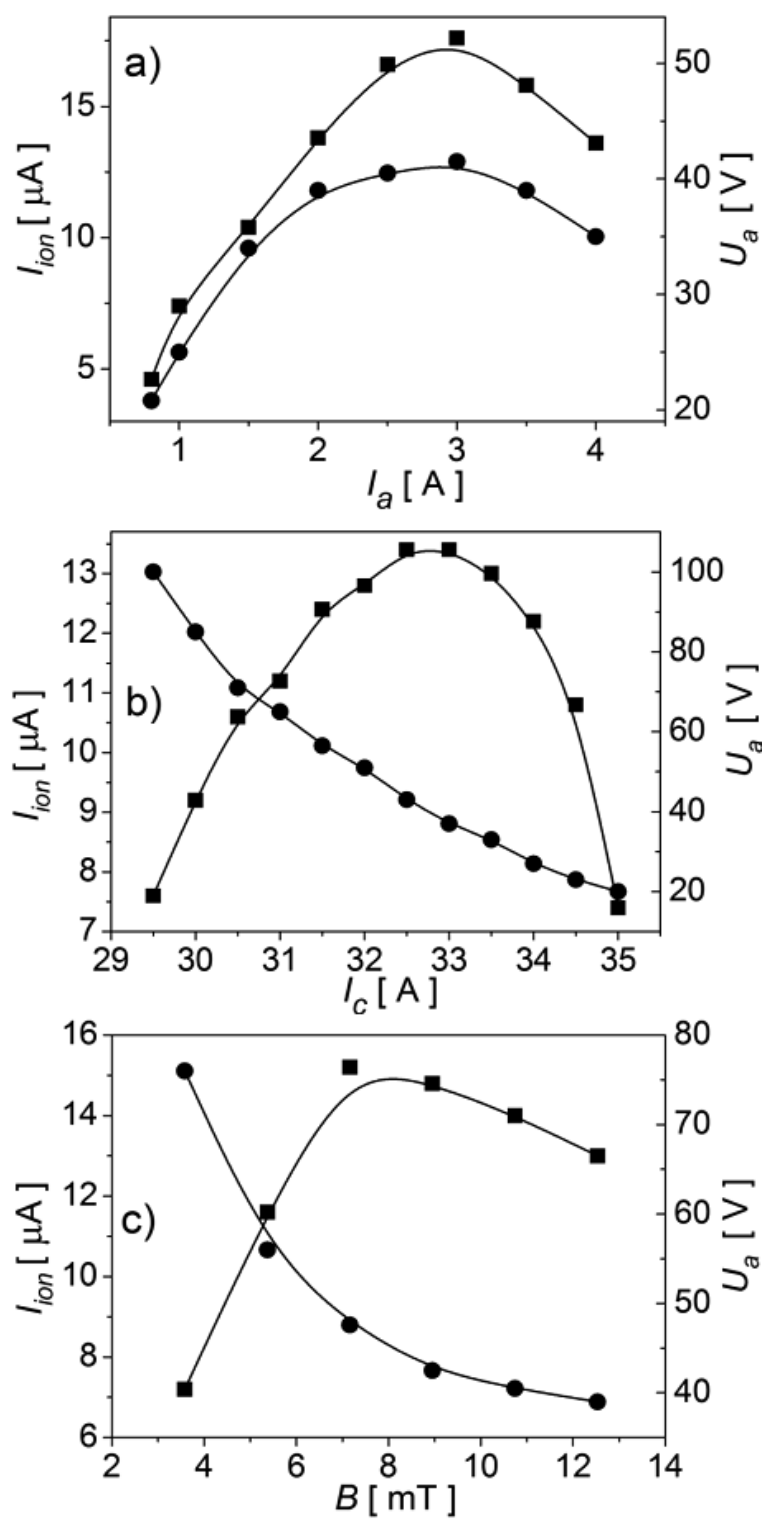

Fig. 3. The same as in Fig. 2 but for $\mathrm{CHCl}_{3}$ as the feeding substance.

Figures $2 \mathrm{a}$ and $3 \mathrm{a}$ present the influence of filament current on the separated $\mathrm{Mo}^{+}$beam current. On the one hand, the larger is $I_{\mathrm{c}}$, the more electrons are emitted from the filament, and the larger is the ionization probability. On the other hand, increasing electron density reduces the discharge voltage $U_{\mathrm{a}}$ (see the $U_{\mathrm{a}}\left(I_{\mathrm{c}}\right)$ dependences shown in the same figures), and consequently, reduces also the electron energy. As a result ionization efficiency degrades when $U_{\mathrm{a}}$ is too low. One deals here with the two above-mentioned concurrent tendencies, which result in a broad peak of $I_{\text {ion }}\left(I_{\mathrm{c}}\right)$ curve with a maximum for $I_{\mathrm{c}}=31 \mathrm{~A}\left(\mathrm{CCl}_{4}\right)$ and $I_{\mathrm{c}}=32.5 \mathrm{~A}\left(\mathrm{CHCl}_{3}\right)$. The optimal value of $U_{\mathrm{a}}$ is in the range $40-50 \mathrm{~V}$, as previously.

The dependences of $\mathrm{Mo}^{+}$beam current and discharge voltage on a magnetic flux density in the chamber were also measured in order to estimate the optimal value of magnetic flux density (or the electromagnet current). Results are shown in Figs. 2c and 3c. The magnetic flux density was measured inside the electromagnet coil using the LakeShore model 450 gaussmeter. In both cases one can see maxima of $I_{\text {ion }}(B)$ curves near $7 \mathrm{mT}$. External magnetic field compensates partially the field from the filament. The total magnetic field makes electron to move along spiral trajectories. This effect improves source efficiency, but up to some level, as one can observe the decrease of discharge voltage with $B$.

\section{Conclusions}

In the paper a new method of $\mathrm{Mo}^{+}$beam production was presented. It is based on chemical sputtering/etching of mechanical parts of the ion source, mostly the anode by chloride containing arc discharge plasma. The feeding substance was vapors of $\mathrm{CCl}_{4}\left(\right.$ or $\left.\mathrm{CHCl}_{3}\right)$ with small addition of air. It was found that the ion current increases with the discharge current reaching its maximum when discharge voltage is in the range $40-50 \mathrm{~V}$. The dependence of the ion current was also under investigation. The optimal value of the filament current was found near 31 A for both feeding substances. The influence of the magnetic flux density from the surrounding electromagnet was also studied. The maximal values of the beam currents are obtained for $B$ near $7 \mathrm{mT}$.

The maximum $\mathrm{Mo}^{+}$beam current was approximately $18 \mu \mathrm{A}$. Having in mind losses due to the horizontal and vertical beam sweeping during the implantation, the achieved ion source efficiency allows performing $\mathrm{Mo}^{+}$implantations with the fluence below $10^{16}$ ions $/ \mathrm{cm}^{2}$ during a single operating cycle.

\section{References}

[1] I.G. Brown, The Physics and Technology of Ion Sources, Wiley, Weinheim 2004.

[2] B. Wolf, Handbook of Ion Sources, CRC Press Inc, Boca Raton 1995.

[3] S. Prucnal, L. Rebohle, A.N. Nazarov, I.N. Osiyuk, I.P. Tjagulskii, W. Skorupa, Appl. Phys. B 91, 123 (2008).

[4] W. Skorupa, J.M. Sun, S. Prucnal, L. Rebohle, T. Gebel, A.N. Nazarov, I.N. Osiyuk, M. Helm, Diffus. Defect Data B: Solid State Phenom. 108, 755 (2005).

[5] K. Potzger, S. Zhou, F. Eichhorn, M. Helm, W. Skorupa, A. Mücklich, J. Fassbender, T. Herrmannsdörfer, A. Bianchi, J. Appl. Phys. 99, 063906 (2006).

[6] Th. Ganetsos, G.L.R. Mair, C.J. Aidinis, L. Bischoff, Physica B 340-342, 1166 (2003).

[7] M. Kanter, Nucl. Instrum. Methods Phys. Res. B 70, 200 (1992).

[8] S. Gammino, L. Torrisi, G. Ciavola, L. Ando, J. Wolowski, L. Laska, J. Krasa, A. Picciotto, Nucl. Instrum. Methods Phys. Res. B 209, 345 (2003).

[9] J.M. Nitschke, Nucl. Instrum. Methods Phys. Res. A 236, 1 (1985). 
[10] Y.V. Yushkevich, M. Turek, D. Mączka, K. Pyszniak, B. Słowiński, Y.A. Vaganov, Nukleonika 57, 351 (2012).

[11] I.G. Brown, B. Feinberg, J.E. Galvin, J. Appl. Phys. 63, 4889 (1988).

[12] M. Turek, S. Prucnal, A. Droździel, K. Pyszniak, Nucl. Instrum. Methods Phys. Res. B 269, 700 (2011).

[13] A. Pyszniak, A. Droździel, M. Turek, A. Latuszyński, D. Mączka, J. Sielanko, Yu.A. Vaganov, Yu.V. Yushkevich, Instrum. Exp. Tech. 50, 552 (2007).

[14] M. Turek, A. Droździel, K. Pyszniak, S. Prucnal, Nucl. Instrum. Methods Phys. Res. A 654, 57 (2011).

[15] M. Turek, A. Droździel, K. Pyszniak, S. Prucnal, J. Żuk, Przeglad Elektrotechniczny 7, 193 (2010) (in Polish).

[16] M. Turek, S. Prucnal, A. Droździel, K. Pyszniak, Rev. Sci. Instrum. 80, 043304 (2009).

[17] C.M. Abreu, M.J. Cristóbal, R. Figueroa, G. Pena, Corrosion Sci. 54, 143 (2012).

[18] W. Zhongda, L. Songmei, Acta Phys.-Chim. Sinica 8, 401 (1992).
[19] C.M. Abreu, M.J. Cristóbal, R. Figueroa, X.R. Novoa, G. Pena, M.C. Perez, Def. Diff. Forum 289-292, 175 (2009).

[20] R. Figueroa, C.M. Abreu, M.J. Cristóbal, G. Pena, Wear 276-277, 53 (2012).

[21] D.Q. Peng, X.D. Bai, X.W. Chen, Q.G. Zhou, X.Y. Liu, P.Y. Deng, Nucl. Instrum. Methods Phys. Res. B 211, 55 (2003).

[22] D.Q. Peng, X.D. Bai, B.S. Chen, Mater. Chem. Phys. 90, 166 (2005).

[23] A.K. Rai, R.S. Bhattacharya, S.C. Kung, J. Appl. Phys. 68, 5169 (1990).

[24] H. Koivisto, J. Arje, M. Nurmia, Rev. Sci. Instrum. 69, 785 (1998).

[25] D.S. Fischl, D.W. Hess, J. Vac. Sci. Technol. B 6, 1577 (1988).

[26] T. Hosoya, S. Ohfuji, T. Shibata, J. Electrochem Soc. 131, 1135 (1984). 